\title{
Norbert Bolz, Zurück zu Luther
}

\section{Gérald Chaix}

\section{OpenEdition \\ Journals}

Édition électronique

URL : http://journals.openedition.org/ifha/9241

DOI : $10.4000 /$ ifha. 9241

ISSN : 2198-8943

Éditeur

IFRA - Institut franco-allemand (sciences historiques et sociales)

\section{Référence électronique}

Gérald Chaix, « Norbert Bolz, Zurück zu Luther », Revue de l'IFHA [En ligne], Date de recension, mis en ligne le 20 juin 2018, consulté le 24 septembre 2020. URL : http://journals.openedition.org/ifha/9241 ; DOI : https://doi.org/10.4000/ifha.9241

Ce document a été généré automatiquement le 24 septembre 2020.

(CIFHA 
Norbert Bolz, Zurück zu Luther

Gérald Chaix

RÉFÉRENCE

Norbert Bolz, Zurück zu Luther, Paderborn: Wilhelm Finck, 2016, 141 p., 19,90€ 
Le petit livre de Norbert Bolz, professeur de communication à la Technische Universität de Berlin, théologien à ses heures, de confession évangélique, s'apparente plus à un essai constitué de vingt-et-un brefs chapitres et à une profession de foi. Pour l'auteur, qui s'inscrit explicitement dans la lignée de Kierkegaard, il s'agit de mettre à l'épreuve l'« humanitarisme sentimental » actuel et de restituer le caractère novateur de Luther dans un monde qui a perdu l'expérience de Dieu. Très classiquement, il oppose la Loi à l'Évangile, rappelle la «folie » de la Parole évangélique, insiste sur le fait que Jésus-Christ suffit et que c'est par Lui seul que l'on peut atteindre Dieu. Il reconnaît les obstacles qui s'opposent à la croyance : la traditionnelle question du mal et les problèmes que le

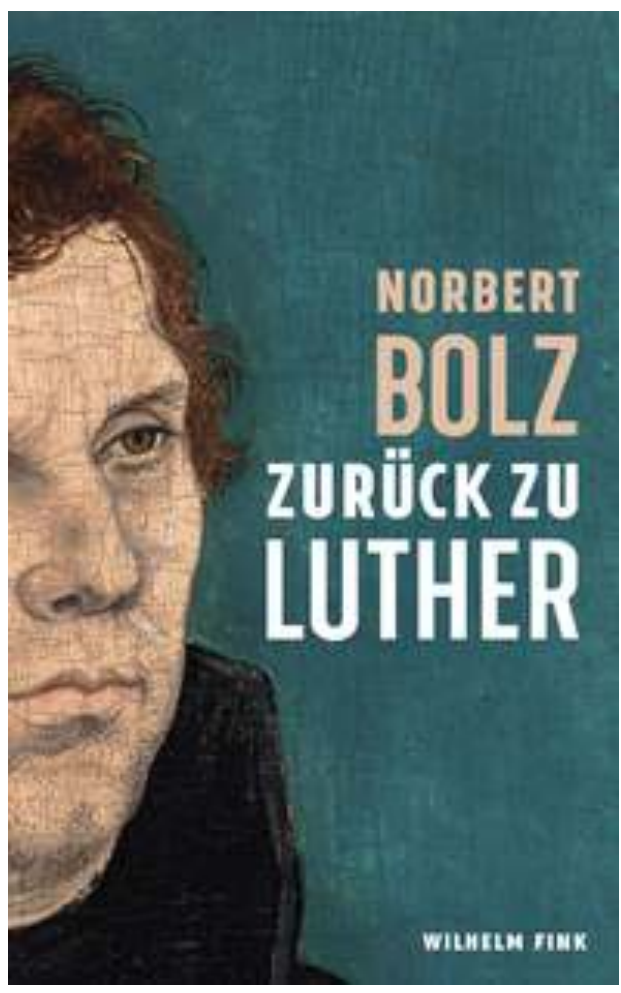
christianisme s'est imposés à lui-même la prédestination, la justification,

l'intériorité. Il s'interroge sur la notion de « règne de Dieu », suggère que s'il n'y a pas de libre arbitre par rapport à Dieu et à son propre salut, conformément à l'orthodoxie luthérienne, il en existe un pour ce qui a trait aux affaires séculières. Il affirme que l'obéissance due à Dieu n'est pas servilité mais loyauté.

Devenu invisible dans le monde, Dieu continue de se révéler par la Parole : c'est un Dieu qui fait douter mais qui donne aussi à espérer. Qu'est-ce que le péché ? le péché originel ? la présence de Satan? L'auteur admet qu'il est difficile de croire à la naissance virginale, à la résurrection et au diable. Mais il faut résister, selon lui, à la tentation de penser que Dieu n'est qu'une illusion et qu'Il relève de la sphère privée. La Réformation exclut la révolution. Mais la théorie des deux règnes aboutit à l'autonomisation du politique, car le chrétien, selon Luther, est tout à la fois citoyen du monde et citoyen de la cité de Dieu. Le chrétien use du monde comme s'il n'en était pas. Mais la dimension eschatologique qui sous-tend cette attitude s'est intériorisée. Le monde de Luther n'est pas vide, comme le croit Walter Benjamin. Il est dénué de valeur. La justification n'est jamais un dû. Dieu seul accorde sa grâce. Ce qui est aujourd'hui, il est vrai, difficile à admettre. Tout comme d'ailleurs l'amour du prochain! N. Bolz rappelle l'importance de l'oralité. Il souligne également la radicalité du christianisme et évoque la nostalgie de l'absolu. Celle d'un pari, déjà énoncé par Blaise Pascal, d'une «folie », déjà annoncée par l'apôtre Paul. 
INDEX

Index chronologique : Période moderne

Thèmes : Histoire religieuse ; Histoire des mentalités

\section{AUTEURS}

\section{GÉRALD CHAIX}

Université de Tours, UMR 7323 